\title{
Diagnostic Utility of p62 Expression in Intranuclear Inclusions in Thyroid Core Needle Biopsy Specimens
}

\author{
HYO JUNG AN ${ }^{1,2,3}$, MIN HYE KIM ${ }^{4}$, JI MIN NA ${ }^{4}$, JUNG WOOK YANG $2,3,4$, \\ HYE JIN BAEK ${ }^{5,6,7}$, KYEONG HWA RYU $^{5,6,7}$ and DAE HYUN SONG ${ }^{1,2,3}$ \\ ${ }^{1}$ Department of Pathology, Gyeongsang National University Changwon Hospital, Changwon, Republic of Korea; \\ ${ }^{2}$ Department of Pathology, Gyeongsang National University School of Medicine, Jinju, Republic of Korea; \\ ${ }^{3}$ Department of Pathology, Gyeongsang Institute of Health Science, Jinju, Republic of Korea; \\ ${ }^{4}$ Department of Pathology, Gyeongsang National University Hospital, Jinju, Republic of Korea; \\ ${ }^{5}$ Department of Radiology, Gyeongsang National University Changwon Hospital, Changwon, Republic of Korea; \\ ${ }^{6}$ Department of Radiology, Gyeongsang National University School of Medicine, Jinju, Republic of Korea; \\ ${ }^{7}$ Department of Radiology, Institute of Health Sciences, \\ Gyeongsang National University School of Medicine, Jinju, Republic of Korea
}

\begin{abstract}
Background/Aim: Core needle biopsy (CNB) has been widely used as an alternative method to ultrasoundguided fine-needle aspiration cytology for histological diagnosis of thyroid specimens. However, nuclear artifactual vacuoles (NuVas) produced during tissue processing can be very difficult and sometimes impossible to distinguish from intranuclear inclusions (NuIns). P62 is an autophagy receptor that recognizes, targets, and eliminates toxic cellular materials during autophagy. Herein, we examined the utility of p62 immunohistochemical staining to detect NuIns in thyroid core needle biopsy specimens. Patients and Methods:Thirty-five thyroid CNB slides from 32 patients and corresponding resection specimens stained with hematoxylin and eosin were reviewed by two pathologists. The immunohistochemical staining pattern of p62 was used to differentiate NuIns from NuVas. The diameter of each nucleus (A) and NuIn (B) was measured, and the number of p62-expressing NuIn-positive (p62In) cells was counted using $1 / 2(B / A)$ and $1 / 3(B / A)$ criteria. The criterion of $1 / 3$ includes NuIns larger than $1 / 3$ and smaller than $1 / 2$ of the nuclear diameter. The criteria of 1/2 includes NuIns larger than 1/2 of the nuclear diameter. Results: By applying the
\end{abstract}

This article is freely accessible online.

Correspondence to: Dae Hyun Song, MD, Department of Pathology, Gyeongsang National University School of Medicine, 15 Jinju-daero 816 Beon-gil, Jinju 660-751, Republic of Korea. Tel: +82 552143150, Fax: +82 552143174, e-mail: golgy@ hanmail.net

Key Words: Needle biopsy, thyroid,papillary carcinoma, follicular adenoma, p62, intranuclear inclusion.
1/2 criterion, there were no p62In cells in follicular adenoma (FA) samples. However, in papillary thyroid carcinoma (PTC) samples, 22 of 25 specimens exhibited p62In cells. The sensitivity and specificity to distinguish FA from PTC using the $1 / 2$ criterion were 0.88 and 1.00 , respectively. By applying the 1/3 criterion, there was one p62In cell hit in FA samples. However, 23 of 25 PTC specimens showed p62In cells. The sensitivity and specificity to distinguish FA from PTC using the $1 / 3$ criterion were 1.00 and 0.90 , respectively. Conclusion: P62 is a useful marker for distinguishing FA and PTC based on CNB specimens. We suggest the 1/2 criteria for identifying p62In cells.

Ultrasound-guided fine-needle aspiration cytology (FNAC) is a common and useful method for diagnosing thyroid nodules (1). If FNAC fails or is inconclusive, patients should receive repeated FNAC or diagnostic surgery $(2,3)$. Ultrasound-guided thyroid core needle biopsy (CNB) is widely used to diagnose lesions with inconclusive or atypia of undetermined significance FNAC results (3-6). CNB has the benefit of allowing for immunohistochemical staining (IHC) and observation of the features of stromal invasion. However, artifactual nuclear vacuoles (NuVas), intranuclear artifacts derived from the production of hematoxylin and eosin (HE)-stained slides, can be very difficult and sometimes impossible to distinguish from intranuclear inclusions (NuIns). NuIns are important pathological features for the diagnosis of papillary thyroid carcinoma (PTC). In PTC, NuIns have more sharply delineated rims than NuVas, whereas $\mathrm{NuVas}$ are more irregular in shape and only lightly stained withHE (2). Schwertheim et al. (7) used IHC of several autophagy-associated proteins, including p62, to detect NuIns in PTC. Theyproved that NuIns are entirely 
closed on both two and three dimensions with no connection to the cytoplasm. As the patient outcomes, surgical methods, and postoperative workups are different, it is very important to distinguish between PTC and a follicular neoplasm, particularly follicular adenoma (FA), prior to surgery. Herein, we examined criteria to differentiate NuIns from $\mathrm{NuVas}$ and between PTC and FA in CNB specimens using IHC of p62.

\section{Patients and Methods}

Case selection. A total of $35 \mathrm{HE}$-stained slides of thyroid CNBs from 32 patients were reviewed by two pathologists. These patients underwent thyroidectomy for PTC or FA at the Gyeongsang National University Changwon Hospital, South Korea between January 2016 and December 2018. Each CNB slide and matched surgical specimen were reviewed. Patient information is summarized in Table I. This study was approved by the Institutional Review Board of Gyeongsang National University Changwon Hospital (GNUCH-2020-09-008). Informed consent was obtained from the patient.

Immunohistochemistry and nuclear pattern analysis. All $35 \mathrm{CNB}$ specimens were reviewed, and their tumoral proportions were recorded (Table I). IHC was performed using an automated immunostainer (Benchmark Ultra, Ventana Medical Systems Inc., Tucson, AZ, USA) with a p62 monoclonal antibody (1:2000; ab56416, Abcam, Cambridge, MA, USA). The IHC nuclear patterns of p62 were evaluated to differentiate NuIns from NuVas. The diameters of each nucleus (A) and NuIn (B) were measured, and the number of p62-expressing NuIn-positive (p62In) cells was determined in each CNB specimen using the criteria of $1 / 2(\mathrm{~B} / \mathrm{A})$ and $1 / 3(\mathrm{~B} / \mathrm{A})$. The criterion of $1 / 3$ includes NuIns larger than $1 / 3$ and smaller than $1 / 2$ of the nuclear diameter. The criteria of $1 / 2$ includes NuIns larger than $1 / 2$ of the nuclear diameter (Figure 1A). The sensitivity and specificity of each criterion were analyzed (Table I).

\section{Results}

Intranuclear inclusions and nuclear vacuoles in core needle biopsies. Numerous NuVas were detected in the HE-stained slides of CNBs from FAs, accounting for up to $70 \%$ of the volume of each nucleus. In particular, $\mathrm{NuVas}$ were detected in the nuclei of endothelial cells (Figure 1B), and the NuVas were more than half the diameter of the nucleus of the follicular cells (Figure 1B). In FA samples, several NuVas appeared similar to NuIns in the HE-stained slides, and it was impossible to distinguish $\mathrm{NuVas}$ from NuIns. The opinions of two pathologists about NuVas in FA samples were unconsented in the blind test. Conversely, in PTC samples, the NuIns were easily detected. However, NuVas were also detected in PTC samples (Figure 1C), and the pathologists had difficulty in distinguishing NuIns from NuVas in the blind test.

Comparison of p62 expression to other biomarkers. We examined the hematoxylin and eosin-stained slides (Figure 2A) and expression of the biomarkers Galectin-3 (Figure 2B), CK19 (Figure 2C), and p62 (Figure 2D), and found that their
Table I. Information of 35 core needle biopsies used in the study.

\begin{tabular}{|c|c|c|c|c|}
\hline No. & Dx. & Proportion & $1 / 2$ p62In & 1/3 p62In \\
\hline 1 & $\mathrm{~F}$ & 90 & 0 & 0 \\
\hline 2 & $\mathrm{~F}$ & 100 & 0 & 0 \\
\hline 3 & $\mathrm{~F}$ & 90 & 0 & 0 \\
\hline 4 & $\mathrm{~F}$ & 60 & 0 & 0 \\
\hline 5 & $\mathrm{~F}$ & 60 & 0 & 1 \\
\hline 6 & $\mathrm{~F}$ & 60 & 0 & 0 \\
\hline 7 & $\mathrm{~F}$ & 40 & 0 & 0 \\
\hline 8 & $\mathrm{~F}$ & 60 & 0 & 0 \\
\hline 9 & $\mathrm{~F}$ & 90 & 0 & 0 \\
\hline 10 & $\mathrm{~F}$ & 90 & 0 & 0 \\
\hline 11 & $\mathrm{P}$ & 70 & 9 & 23 \\
\hline 12 & $\mathrm{P}$ & 60 & 14 & 51 \\
\hline 13 & $\mathrm{P}$ & 10 & 2 & 4 \\
\hline 14 & $\mathrm{P}$ & 20 & 0 & 0 \\
\hline 15 & $\mathrm{P}$ & 60 & 0 & 0 \\
\hline 16 & $\mathrm{P}$ & 60 & 26 & 81 \\
\hline 17 & $\mathrm{P}$ & 50 & 1 & 1 \\
\hline 18 & $\mathrm{P}$ & 60 & 30 & 99 \\
\hline 19 & $\mathrm{P}$ & 40 & 1 & 2 \\
\hline 20 & $\mathrm{P}$ & 30 & 1 & 6 \\
\hline 21 & $\mathrm{P}$ & 30 & 2 & 7 \\
\hline 22 & $\mathrm{P}$ & 40 & 0 & 1 \\
\hline 23 & $\mathrm{P}$ & 70 & 11 & 23 \\
\hline 24 & $\mathrm{P}$ & 70 & 74 & 160 \\
\hline 25 & $\mathrm{P}$ & 15 & 4 & 20 \\
\hline 26 & $\mathrm{P}$ & 50 & 12 & 70 \\
\hline 27 & $\mathrm{P}$ & 50 & 6 & 22 \\
\hline 28 & $\mathrm{P}$ & 30 & 19 & 23 \\
\hline 29 & $\mathrm{P}$ & 60 & 5 & 12 \\
\hline 30 & P-f & 50 & 3 & 6 \\
\hline 31 & P-f & 70 & 2 & 5 \\
\hline 32 & P-f & 60 & 8 & 13 \\
\hline 33 & P-f & 40 & 11 & 31 \\
\hline 34 & P-f & 70 & 151 & 253 \\
\hline 35 & P-f & 40 & 4 & 11 \\
\hline Sens & $1 \mathrm{p}$ & & $22 / 25(0.88)$ & $23 / 25(0.92)$ \\
\hline Spec & of p6 & & $10 / 10(1.00)$ & $9 / 10(0.90)$ \\
\hline
\end{tabular}

No, Specimen number; Dx, diagnosis of surgical specimen; proportion, tumor proportion of $\mathrm{CNB}$; $1 / 2 \mathrm{p} 62 \mathrm{In}$, number of p62In of CNB in $1 / 2$ $(\mathrm{B} / \mathrm{A})$ criterion; $1 / 3$ p62In, number of p62In of $\mathrm{CNB}$ in $1 / 3(\mathrm{~B} / \mathrm{A})$ criterion; F, follicular adenoma; P, papillary carcinoma, classical; P-f, papillary carcinoma, follicular variant; *surgically diagnosed papillary carcinomas are condition positive and surgically diagnosed follicular adenomas are condition negative.

expression patterns differed in the PTC needle biopsy specimen. In hematoxylin and eosin-stained PTC tissues (Figure 2A), NuVas and NuIns were barely discriminated. In PTC immune-stained for Galectin-3, the NuIns were highlighted clearly from the weaker nuclear and cytoplasmic staining patterns of cancer cells. However, the total number of NuIns was very small, so many of the true NuIns were hardly stained. In CK19 immunostaining, both NuIns and cytoplasmic staining patterns of cancer cells appeared 
A

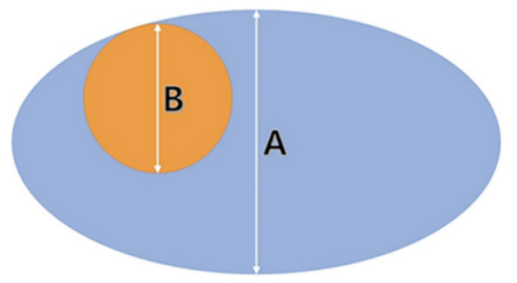

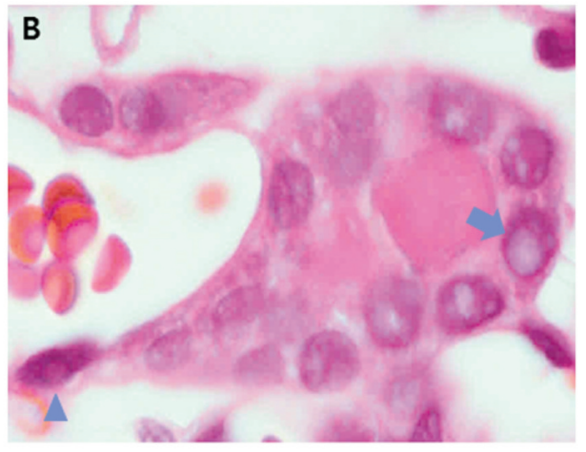

Figure 1. Intranuclear inclusion (NuIn) criteria and Nuclear artefactual vacuoles (NuVa). (A) The criteria of 1/2 includes NuIns larger than 1/2 of the nuclear diameter. (B) NuVa is detected in the nuclei of the endothelial cells (arrowhead) $(\times 1,000$, hematoxylin and eosin). NuVas are more than half the diameter of the nucleus of follicular cells (arrow) of follicular adenoma. (C) NuVas are also detected in papillary carcinoma samples $(\times 1,000$, hematoxylin and eosin).
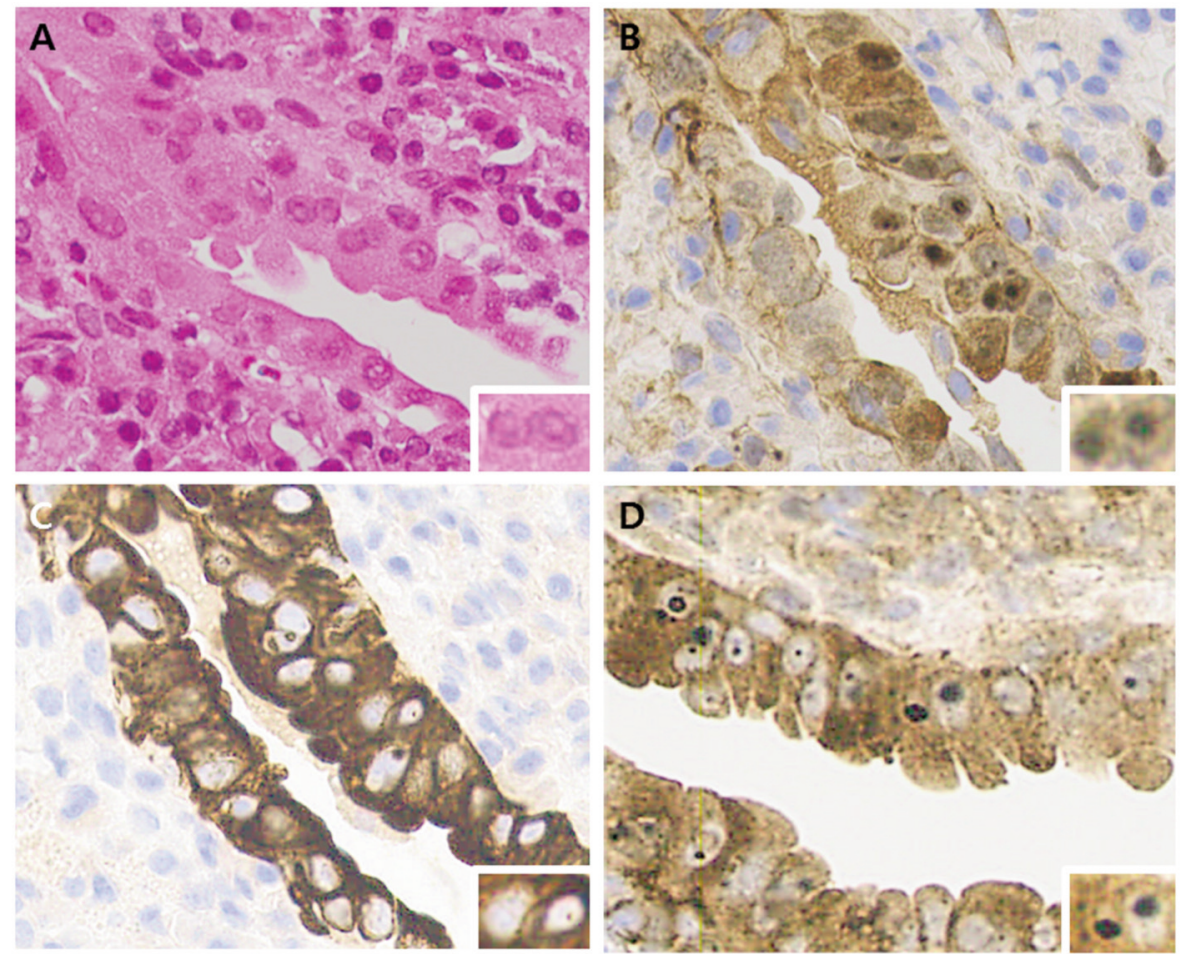

Figure 2. Comparison of p62 expression to that of other biomarkers in the PTC needle biopsy specimen. Representative section of hematoxylin and eosin-stained slide of PTC needle biopsy specimen (Figure 2A) ( $\times 400$, hematoxylin and eosin). Small numbers of NuIns were distinguishable in Galectin-3 staining (Figure 2B) (x400). For CK19 (Figure 2C) (x400), both NuIns and cytoplasmic staining of tumor cells showed such strong intensity. However, there were someNuIns that were unstained (an inlet of Figure $2 C)(\times 1,000)$ though they were obvious from hematoxylin and eosin-stained slides (an inlet of Figure $2 A)(\times 1,000)$. In p62 staining (Figure $2 D)(\times 400)$, there were much more NuIns highlighted and they were easily discriminated by their strong intensity with better contrast to the background.

strongly. The number of NuIns was larger than that visualized with Galectin-3 staining. However, some of the NuIns were missing, resulting in much smaller numbers of NuIns compared to p62 staining. p62 staining of NuIns showed the most ideal patterns in terms of total numbers (much more than Galectin-3 and CK19) and clear discrimination (the strongest staining intensity was highlighted over the cytoplasmic staining of the tumor cells). Therefore, we chose p62 expression for discriminating and applying the $1 / 3$ and $1 / 2$ criterion on NuIns of the PTC CNB specimen. 

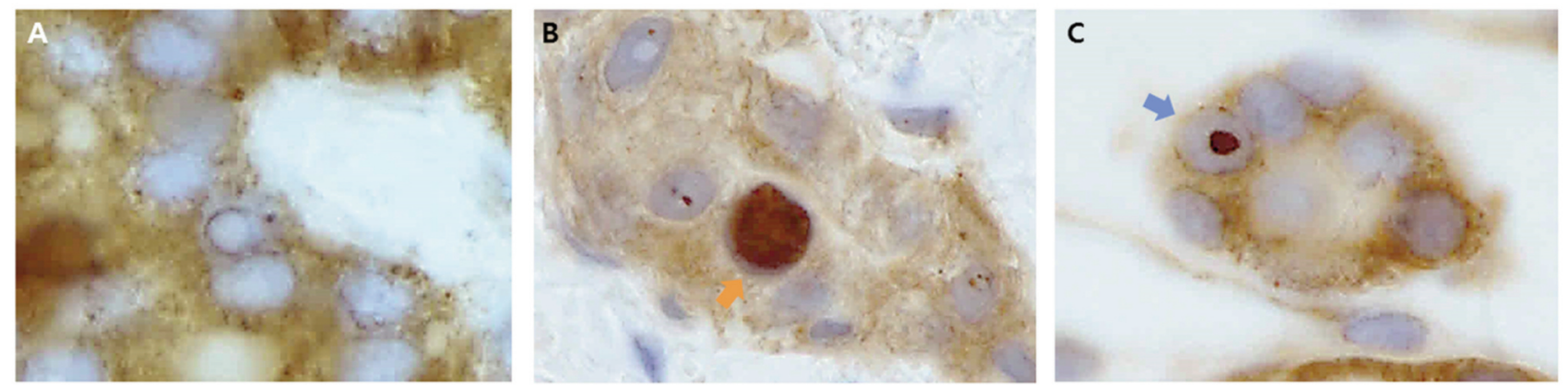

Figure 3.p62 expression in intranuclear inclusions (InNu). (A) By applying the 1/2 criterion, there is no p62-expressing NuIn-positive (p62In) cells in follicular adenoma $(F A)(\times 1,000)$. (B) Most of the papillary carcinoma specimens exhibit p62In cells (arrow) $(\times 1,000)$. (C) By applying the 1/3 criterion, there is one FA with p62In cells in the biopsy specimen $(\times 1,000)$.
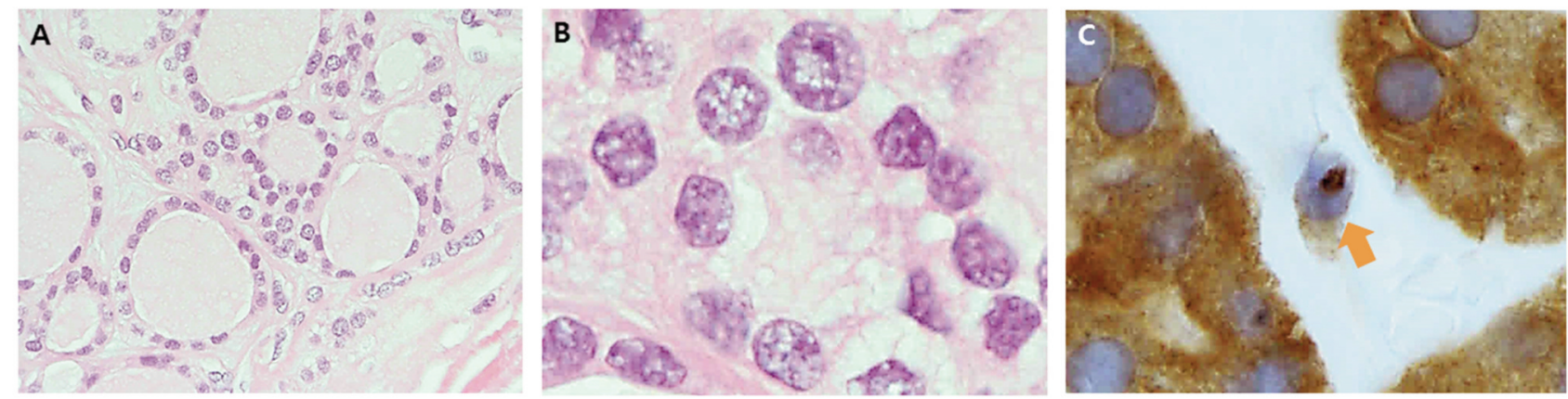

Figure 4. p62 expression in follicular adenoma (FA). (A) A case of typical pathologic features of FA( $\times 400$, hematoxylin and eosin). (B) No intranuclear inclusions in the deeper slide sections of the same tumor $(\times 1,000$, hematoxylin and eosin). (C) p62-expressing NuIn-positive cells (arrow) in the endothelial cells in another FA case $(\times 1,000)$.

p62 expression in intranuclear inclusions. When applying the $1 / 2$ criterion, there were no p62In cells in FA specimens (Figure 3A). However, 22 of 25 PTC specimen exhibited p62In cells (Figure $3 \mathrm{~B}$ ). The sensitivity and specificity in distinguishing FA from PTC using p62In cells using the 1/2 criterion were 0.88 and 1.00 , respectively. Three PTCs without p62In cells in the CNB also had rare NuIns in the surgical specimen. When we applied the $1 / 3$ criterion, there was one FA case with p62In cells in the CNB (Figure 3C). The size of the resected tumor in this case was $0.8 \mathrm{~cm}$. The tumor had typical pathological features of FA (Figure 4A), and there were no NuIns in the deeper slide sections of the tumor (Figure 4B). Meanwhile, there were p62In cells in the endothelial cells in the CNB of another FA case. These endothelial cells fulfilled the $1 / 3$ criterion (Figure 4C). Twenty-three of the 25 PTC specimens showed p62In cells using the $1 / 3$ criterion. The sensitivity and specificity to distinguish FA from PTC using the $1 / 3$ criterion were 0.92 and 0.90 , respectively. The two PTC cases without p62In cells also had rare NuIns in the surgical specimen. When examining CNBs of follicular variant papillary carcinoma cases, six of six specimens showed p62In cells, regardless of which criteria were applied.
The sensitivity and specificity to distinguish FA from follicular variant papillary carcinoma using p62In using either criteria were 1.00 and 1.00 , respectively.

\section{Discussion}

FNAC is the standardized preoperative diagnostic modality for thyroid nodules $(3,8-10)$. Thyroid CNB was introduced as an alternative method in South Korea in the 1990s and has since been widely used $(3,11)$. Samples collected by CNB contain more abundant tissue and maintain the architectural characteristics of the nodules; therefore, non-diagnostic or inconclusive findings are less common than in FNAC, which generally provides scattered and structurally dissolved tissue samples $(3,12)$. Although CNB sampling may not be the optimal choice for all thyroid nodules, it is widely accepted as the best method to diagnose samples for which previous FNAC results were inconclusive or atypia of undetermined significance (3-6). The most advantageous characteristic of CNB over FNAC is that it is optimized to distinguish specific cancers, such as PTC, medullary carcinoma, lymphoma, and metastatic carcinoma, through IHC (2). 
However, the NuVas that mimic NuIns in PTC are a major limitation of CNB. Jung et al. stated that NuIns in PTC are sharply delimited, round in shape, and nuclear membranebounded, whereas NuVas are irregular in shape and palelooking (2). However, it is sometimes impossible to distinguish true NuIns from NuVas using only these parameters, since NuIns do not appear in all cancer cells and have different sizes, shapes, and numbers.

The mechanism of NuIn formation is yet to be established. Nuclear inclusions can also be called pseudodenuded holes, nuclear holes, and NuIns, and there can be one or two within a nucleus (13). In 2010, Fischer et al. reported the diagnostic importance of the nuclear envelope in cancer (14). They classified nuclear envelope structural changes into three groups: nuclear envelope changes associated with chromosomal instability (cell-to-cell variations in nuclear envelope size, shape, and deep infoldings); conserved nuclear envelope structural features within an unstable genetic population (increased nuclear/cytoplasmic ratio and fragile nuclear lamina of small cell carcinoma); and nuclear envelope changes directly associated with activation of specific oncogenes (long nuclear infolding or nuclear groove and intranuclear cytoplasmic inclusions induced by BRAF, RET/PTC, and TRK/PTC in PTC). They explained intranuclear cytoplasmic inclusion formation in the third group as a phenomenon of long inward folding of the nuclear envelope and spherical cytoplasmic invagination partially protruding into the nucleus (14).

Since it is difficult to discriminate NuVas from NuIns in hematoxylin and eosin-stained slides of PTC core needle biopsy specimens (Figure 2A), we compared different biomarkers of the PTC, including Galectin-3 (Figure 2B), CK19 (Figure 2C), and p62 (Figure 2D). There were very small numbers of NuIns in Galectin-3 staining (Figure 2B). For CK19, both NuIns and cytoplasmic staining intensity of tumor cells were overwhelming (Figure 2C), however, there were some NuIns, that were not stained (Figure 2C), though they were obvious from hematoxylin and eosin-stained slides (Figure 2A). With p62 staining (Figure 2D), more NuIns were highlighted and could be discriminated by their strong intensity with more contrast (Figure 2D). Based on the previous study of Fischer et al. (14), we hypothesized that the nuclear envelope changes should be directly associated with activation of specific oncogenes (BRAF, RET/PTC, and TRK/PTC) or biomolecular changes in PTC and that it is more reasonable to show a different aspect of staining patterns in the cytoplasm from NuIns. We thought that p62 best reflected the mechanism of NuIns formation, therefore, we chose p62 staining to evaluate NuIns in the CNB of PTC specimens.

Based on the guidelines suggested by previous studies, we numerically evaluated the extent to which NuIns filled the nucleus using $1 / 2$ or $1 / 3$ criteria. The diameters of each nucleus (A) and NuIn (B) were measured, and the number of p62-expressing NuIn-positive (p62In) cells was determined in each $\mathrm{CNB}$ specimen using the criteria of $1 / 2$ $(\mathrm{B} / \mathrm{A})$ and $1 / 3(\mathrm{~B} / \mathrm{A})$. The criterion of $1 / 3$ includes NuIns larger than $1 / 3$ and smaller than $1 / 2$ of the nuclear diameter. The criteria of $1 / 2$ includes NuIns larger than $1 / 2$ of the nuclear diameter (Figure 1A). The sensitivity and specificity of each criterion were analyzed (Table I). The sensitivity and specificity in distinguishing FA from PTC using the 1/2 criterion were 0.88 and 1.00 , respectively. The sensitivity and specificity in distinguishing FA from PTC using the $1 / 3$ criterion were 0.92 and 0.90 , respectively. Finally, the sensitivity and specificity to distinguish FA from follicular variant papillary carcinoma using both the $1 / 2$ and $1 / 3$ criteria were 1.00 and 1.00 , respectively. Hence, the $1 / 2$ criteria had higher specificity in distinguishing PTC from FA than the $1 / 3$ criteria, and applying either criterion would be useful in distinguishing FA from follicular variant papillary carcinoma. Therefore, we agree with Schwertheim et al. (7) that p62 is a useful marker for NuIns. However, since NuIns have different sizes, shapes, and numbers, distinct criteria for evaluating NuIns are mandatory. We suggest only assessing NuIns above certain sizes using the $1 / 2$ criteria based on specificity in distinguishing PTC from FA in our study.

There have been several attempts to distinguish NuIns from NuVas using IHC to diagnose PTC $(7,15,16)$. Schwertheimet al. (7) examined the expression of several autophagy-associated proteins in NuIns, including LC3B, ubiquitin, cathepsin D, p62/sequestosome 1, and cathepsin B. They proved that NuIns are entirely closed on both two and three dimensions with no connection to the cytoplasm. This is why p62 is found only in the NuIn and not in the cytoplasm. In addition, p62 is not found in vacuoles because they are not produced by cytoplasmic invagination, which is the main source of p62 and its cargo. Finally, they concluded that the BRAF V600E mutation was significantly associated with the number of NuIns in PTC $(p=0.042)$ and with IHC patterns of autophagy-associated proteins in NuIns $(p \leq 0.035)$. They assert that the expression of autophagyassociated proteins, degenerated organelles, and lysosomal proteases within NuIns indicate that they contribute to autophagy and proteolysis.

Autophagy is a condition in which severely undernourished cells arrest their growth and cannibalize their cytoplasmic organelles, proteins, and membranes for energy (17). Some genes that promote autophagy are tumor suppressor genes, that is, loss of these genes enhances tumor growth. However, under severe nutrient-deficient conditions, tumor cells might use autophagy to enter a state of metabolic hibernation, allowing them to survive for increased periods of time or under stress. Therefore, autophagy can be protumorigenic depending on the controlling signaling pathways (17). P62, also known as sequestosome 1 , is an autophagy receptor that forms autophagosomes that engulf and cannibalize damaged 
organelles, toxic proteins, and microorganisms in the cytoplasm. When autophagosomes are fused with lysosomes, the digested cargo and p62 are degraded $(18,19)$. P62 recognizes, targets, and eliminates toxic cellular materials during autophagy. However, p62 is not always beneficial for normal cell homeostasis. Under normal conditions, basal autophagy constantly eliminates p62 and related cargo from the cytoplasm. When autophagy is insufficient, p62 and related cargo accumulate in the cytoplasm, which contributes to a pathological status (18). A previous study found that when p62 was removed, liver cell hypertrophy and lysosomal enzymes originating from oxidative stress were reduced (18). We designed this study based on previous reports that p62 accumulation is pathogenic. As Schwertheim et al. (7) concluded that p62 expression in NuIns indicates their contribution to autophagy, we hypothesized that p62In cells may be created due to accumulation of p62 not eliminated by autophagy, and that they drive pathological changes in the thyroid tissue in PTC. When stimulated by growth factors, normal cells generally increase their glutamine and glucose uptake as energy sources. However, in cancer, oncogenic mutations associated with growth factor signaling and other intermediate factors such as RAS, MYC, or BRAF constitutively activate metabolic pathways, resulting in tumor progression (17). The combination of deterioration of autophagy above a certain level of p62 accumulation and growth factor-associated oncogenic mutations, such as BRAF, may contribute to the formation of p62In cells in PTC.

To the best of our knowledge, this is the first report to propose distinctive size criteria for NuIns in CNB samples of PTC. The limitation of this study was the small number of cases. We only selected patients who had undergone both $\mathrm{CNB}$ and resection in our hospital. The association of BRAF status and p62Ins cells using the $1 / 2$ criteria in thyroid cancers should be further evaluated in resected specimens to reveal the mechanism of NuIn formation in thyroid cancer. In conclusion, the diagnostic usefulness of p62Ins cells in CNB specimens of the thyroid was elucidated in this study. We recommend the $1 / 2$ criteria for identifying p62In cells and differentiating PTC and FA.

\section{Conflicts of Interest}

The Authors declare that they have no conflicts of interest.

\section{Authors' Contributions}

HJ An: Project development, data analysis, manuscript writing. $\mathrm{MH}$ Kim: Data collection, manuscript editing. JM Na: Data collection, manuscript editing. JW Yang: Data collection, manuscript editing. HJBaek: Data collection, manuscript editing. KH Ryu: Data collection, manuscript editing. DH Song: Manuscript editing, data analysis, supervision.

\section{References}

1 American Thyroid Association (ATA) Guidelines taskforce on thyroid nodules and differentiated thyroid cancer, Cooper DS, Doherty GM, Haugen BR, Kloos RT, Lee SL, Mandel SJ, Mazzaferri EL, McIver B, Pacini F, Schlumberger M, Sherman SI, Steward DL and Tuttle RM: Revised American Thyroid Association management guidelines for patients with thyroid nodules and differentiated thyroid cancer. Thyroid 19(11): 11671214, 2009. PMID: 19860577. DOI: 10.1089/thy.2009.0110

2 Jung CK, Min HS, Park HJ, Song DE, Kim JH, Park SY, Yoo H, Shin MK and Korean Endocrine Pathology Thyroid Core Needle Biopsy Study Group: Pathology Reporting of Thyroid Core Needle Biopsy: A Proposal of the Korean Endocrine Pathology Thyroid Core Needle Biopsy Study Group. J Pathol Transl Med 49(4): 288-299, 2015. PMID: 26081825. DOI: 10.4132/jptm. 2015.06.04

3 Jung CK and Baek JH: Recent Advances in Core Needle Biopsy for Thyroid Nodules. Endocrinol Metab (Seoul) 32(4): 407-412, 2017. PMID: 29271614. DOI: 10.3803/EnM.2017.32.4.407

4 Na DG, Kim JH, Sung JY, Baek JH, Jung KC, Lee H and Yoo $\mathrm{H}$ : Core-needle biopsy is more useful than repeat fine-needle aspiration in thyroid nodules read as nondiagnostic or atypia of undetermined significance by the Bethesda system for reporting thyroid cytopathology. Thyroid 22(5): 468-475, 2012. PMID: 22304417. DOI: 10.1089/thy.2011.0185

5 Choi YJ, Baek JH, Suh CH, Shim WH, Jeong B, Kim JK, Song DE, Kim TY, Chung KW and Lee JH: Core-needle biopsy versus repeat fine-needle aspiration for thyroid nodules initially read as atypia/follicular lesion of undetermined significance. Head Neck 39(2): 361-369, 2017. PMID: 27704650. DOI: 10.1002/hed. 24597

6 Park KT, Ahn SH, Mo JH, Park YJ, Park DJ, Choi SI and Park SY: Role of core needle biopsy and ultrasonographic finding in management of indeterminate thyroid nodules. Head Neck 33(2): 160-165, 2011. PMID: 20848434. DOI: 10.1002/hed.21414

7 Schwertheim S, Theurer S, Jastrow H, Herold T, Ting S, Westerwick D, Bertram S, Schaefer CM, Kälsch J, Baba HA and Schmid KW: New insights into intranuclear inclusions in thyroid carcinoma: Association with autophagy and with BRAFV600E mutation. PLoS One 14(12): e0226199, 2019. PMID: 31841566. DOI: $10.1371 /$ journal.pone.0226199

8 Cibas ES and Ali SZ: The 2017 Bethesda System for Reporting Thyroid Cytopathology. Thyroid 27(11): 1341-1346, 2017. PMID: 29091573. DOI: 10.1089/thy.2017.0500

9 Haugen BR, Sawka AM, Alexander EK, Bible KC, Caturegli P, Doherty GM, Mandel SJ, Morris JC, Nassar A, Pacini F, Schlumberger M, Schuff K, Sherman SI, Somerset H, Sosa JA, Steward DL, Wartofsky L and Williams MD: American Thyroid Association guidelines on the management of thyroid nodules and differentiated thyroid cancer task force review and recommendation on the proposed renaming of encapsulated follicular variant papillary thyroid carcinoma without invasion to noninvasive follicular thyroid neoplasm with papillary-like nuclear features. Thyroid 27(4): 481-483, 2017. PMID: 28114862. DOI: $10.1089 /$ thy.2016.0628

10 Zagorianakou P, Malamou-Mitsi V, Zagorianakou N, Stefanou D, Tsatsoulis A and Agnantis NJ: The role of fine-needle aspiration biopsy in the management of patients with thyroid nodules. In Vivo 19(3): 605-609, 2005. PMID: 15875783. 
11 Baek JH: Current status of core needle biopsy of the thyroid. Ultrasonography 36(2): 83-85, 2017. PMID: 28301922. DOI: 10.14366/usg. 17018

12 Suh CH, Baek JH, Lee JH, Choi YJ, Kim KW, Lee J, Chung KW and Shong YK: The role of core-needle biopsy in the diagnosis of thyroid malignancy in 4580 patients with 4746 thyroid nodules: a systematic review and meta-analysis. Endocrine 54(2): 315-328, 2016. PMID: 27220941. DOI: 10.1007/s12020-016-0991-9

13 Kaneko C, Shamoto M, Niimi H, Osada A, Shimizu M and Shinzato M: Studies on intranuclear inclusions and nuclear grooves in papillary thyroid cancer by light, scanning electron and transmission electron microscopy. Acta Cytol 40(3): 417422, 1996. PMID: 8669172. DOI: 10.1159/000333892

14 Fischer AH: The diagnostic pathology of the nuclear envelope in human cancers. Adv Exp Med Biol 773: 49-75, 2014. PMID: 24563343. DOI: 10.1007/978-1-4899-8032-8_3

15 Domagala P and Domagala W: Nuclear CK19-immunopositive pseudoinclusions as a new additional objective diagnostic feature of papillary thyroid carcinoma. Pol J Pathol 71(1): 1-6, 2020 PMID: 32429648. DOI: 10.5114/pjp.2020.95410
16 Cracolici V, Krausz $\mathrm{T}$ and Cipriani NA: Ubiquitin immunostaining in thyroid neoplasms marks true intranuclear cytoplasmic pseudoinclusions and may help differentiate papillary carcinoma from NIFTP. Head Neck Pathol 12(4): 522528, 2018. PMID: 29512025. DOI: 10.1007/s12105-018-0905-7

17 Abbas AK and Aster JC: Robbins and Cotran pathologic basis of disease. Tenth edition, International edition. Philladelphia, PA, Elsevier, pp48-49, 300-301, 2021.

18 Rusten TE and Stenmark H: p62, an autophagy hero or culprit? Nat Cell Biol 12(3): 207-209, 2010. PMID: 20190829. DOI: 10.1038/ncb0310-207

19 Kumsta C, Chang JT, Lee R, Tan EP, Yang Y, Loureiro R, Choy EH, Lim SHY, Saez I, Springhorn A, Hoppe T, Vilchez D and Hansen M: The autophagy receptor p62/SQST-1 promotes proteostasis and longevity in C. elegans by inducing autophagy. Nat Commun 10(1): 5648, 2019. PMID: 31827090. DOI: $10.1038 / \mathrm{s} 41467-019-13540-4$

Received January 13, 2021

Revised February 3, 2021 Accepted February 10, 2021 